\title{
Some New Copolymers by Ionic Polymerization
}

\author{
Rolf C. Schulz, Klaus Albrecht, Quynh Van Tran Thi, \\ Johannes NIENBURG, and Dieter ENGEL \\ Institute of Organic Chemistry, University of Mainz, \\ D-65 Mainz, Federal Republic of Germany.
}

(Received April 15, 1980)

\begin{abstract}
In the first part the cationic polymerization of a homologous series of cyclic ether-acetals with ring sizes of 11,14 , and 17 atoms is described. During the polymerization of triethylene glycol formal (TGF) an equilibrium is reached and besides high polymers cyclic oligomers are formed. The oligomers and the polymers are built up of a regular sequence of one oxymethylene unit and three oxyethylene units $\mathrm{f}\left(\mathrm{OCH}_{2}\right)\left(\mathrm{OC}_{2} \mathrm{H}_{4}\right)_{3} \mathrm{f}_{x}$. They are therefore be labelled a "sequenced copolymer." The equilibrium concentrations of the cyclic oligomers with a polymerization degree from 2 to 15 follow the Jacobson-Stockmayer equation. The 14- and 17membered monomers POC and HOC forms cyclic oligomers and high polymers of the general formula $\left[\left(\mathrm{OCH}_{2}\right)_{1}\left(\mathrm{OC}_{2} \mathrm{H}_{4}\right)_{y}\right\}_{x}$ with $y=4$ and $y=5$, respectively. The melting points of these sequenced copolymers with $y=1-5$ are determined. Furthermore, the cationic polymerization of 1,3-dioxacycloundecane (OMF) and 1,3,6,11-tetraoxacyclotridecane (DDF) was studied. ${ }^{1} \mathrm{H}$ and ${ }^{13} \mathrm{C}$ NMR spectra show that again regular copolymers are formed: In the first case an alternating $1: 1$ copolymer $\left.\mathrm{f}\left(\mathrm{OCH}_{2}\right)\left(\mathrm{OC}_{8} \mathrm{H}_{16}\right)\right\}_{x}$, in the latter case a terpolymer with the regular sequence $f\left(\mathrm{OCH}_{2}\right)\left(\mathrm{OC}_{2} \mathrm{H}_{4}\right)\left(\mathrm{OC}_{4} \mathrm{H}_{8}\right)\left(\mathrm{OC}_{2} \mathrm{H}_{4}\right)+_{x}$. The second part deals with the polymerization of 2isopropenylnaphthalene. With maleic anhydride at room temp a charge-transfer complex is formed; at higher temp a Diels-Alder reaction occurs. Only at low temp with UV initiation or redox initiation a copolymer is formed. With cationic catalysts a mixture of dimer, trimer, and tetramer but no polymer is obtained. The anionic polymerization yields polymers with molecular weight from 10,000 to 300,000 and melting points of $280^{\circ} \mathrm{C}$ and glass-transition temp of $220^{\circ} \mathrm{C}$. By "living polymer" techniques block copolymers are available.

KEY WORDS Cationic Polymerization / Anionic Polymerization / Macrocyclic Acetals / 2-Isopropenylnaphthalene / Sequenced Copolymers / Cyclic Oligomers / Charge-Transfer Complexes / High-Performance GelPermeation Chromatography /
\end{abstract}

Several different methods for the synthesis of copolymers are known. The copolymerization of vinyl monomers using free-radical initiators is the oldest and most thoroughly investigated system, this being of great industrial importance. Random copolymers are usually produced by this method, $1: 1$ alternating copolymers being obtained only in few cases. Similarly, Ziegler-Natta catalysts, cationic and anionic initiators all produce essentially copolymers with more or less irregular distribution of monomer units. There are, however, many reasons why regular copolymers are desirable, and several authors have developed special methods to this end. In particular, I would like to mention the work of Gaylord, ${ }^{1}$ Hirooka, ${ }^{2}$ Furukawa, ${ }^{3}$ and
Saegusa. ${ }^{4}$ Thus copolymers with a high content of regular 1:1 sequences have been obtained. Living anionic $^{5}$ or cationic ${ }^{6}$ polymers offer furthermore an excellent means for the production of block copolymers of a defined structure.

It is not the purpose of this lecture to give a general review on this subject, and therefore I only want to present two examples from our own work in which new regular copolymers were produced by means of cationic and anionic polymerization. The first part of this paper will deal with ring-opening polymerization of macrocyclic acetals, while in the second part a new monomer and the results of its copolymerization by both radical and ionic mechanism will be described. 


\section{CATIONIC POLYMERIZATION OF MACROCYCLIC ACETALS}

It is well-known that by cationic polymerization of mixtures of trioxane and ethylene oxide random copolymers of oxymethylene (M) and oxyethylene (E) units are formed. ${ }^{7}$ Homopolymerization of dioxolane on the other hand gives a polymer, which can be regarded as a regular 1:1 alternating copolymer of $\mathrm{M}$ and $\mathrm{E}$ units (eq 1). Similarly the

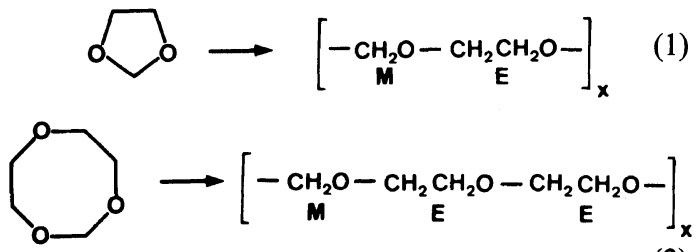

ring-opening of 1,3,6-trioxocane ${ }^{8}$ gives a polymer which consists of regular alternating sequences of one $\mathrm{M}$ and two $\mathrm{E}$ units (eq 2). One should therefore expect that higher homologous or similarly structured cyclic acetals would give copolymers with regular sequences on cationic polymerization. We have accordingly synthesized several such compounds. The polymerization of the following cyclic acetals shall be discussed.<smiles>C1COC[Ge]OCCO1</smiles><smiles>O=C(O)OCCOCCOCCOCCO</smiles><smiles>O=C1COCCOCCOCCOCCO1</smiles><smiles>O=POOCCCCCCO</smiles><smiles>[O+][O-]</smiles>

\section{Polymerization of 1,3,6,9-Tetraoxacycloundecane (TGF)}

This compound and its polymerization was first mentioned by Hill and Carothers ${ }^{9}$ in 1935 but was not further studied for many years. TGF can be prepared in a two-step synthesis starting from triethylene glycol and paraformaldehyde. We have slightly modified the initial synthetic procedure, and obtained the triethylene glycol formal (TGF) monomer with good yield $(65-70 \%)$ and high purity $\left(\mathrm{mp} 27^{\circ} \mathrm{C}\right) .^{10}$

During the last few years the polymerization of
TGF has been studied extensively by Yamashita $e t$ $a l .^{11,12}$ and independently also by our group. ${ }^{13-16}$ The main experimental results of both groups are almost identical. A short review will summarize the important facts and then some new results shall be added.

TGF can be polymerized by various cationic initiators. We have used $\mathrm{BF}_{3}$-etherate, trifluoromethanesulfonic acid, methanesulfonic fluoride $\left(\mathrm{CH}_{3} \mathrm{SO}_{3} \mathrm{~F}\right)$, benzoyl hexafluoroantimonate $(\phi$ $\mathrm{CO}^{\oplus} \mathrm{SbF}_{6}{ }^{\ominus}$ ), or $p$-chlorophenyldiazonium hexafluorophosphate and dichloromethane, toluene, $o$ xylene, dichlorobenzene, and trichlorobenzene as solvents.

The polymers are colourless wax-like materials. They are readily soluble in many organic solvents as well as in water but are insoluble in diethyl ether and higher alcohols.

The ${ }^{1} \mathrm{H}$ NMR spectrum of the monomer shows three sharp singlets due to the protons of the methylene group $(\delta=4.79 \mathrm{ppm})$ and ethylene group $(\delta=3.83$ and $3.69 \mathrm{ppm})$ (Figure 1). In the spectrum of the polymer, the methylene signal shows only a

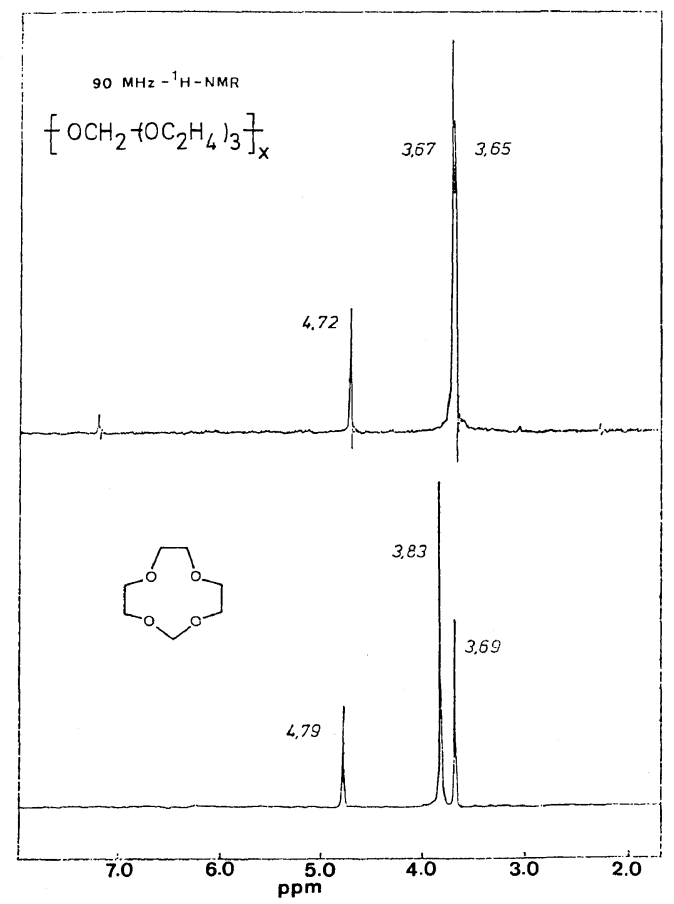

Figure 1. ${ }^{1} \mathrm{H}$ NMR spectra of monomer and polymer 1,3,6,9-tetraoxacycloundecane (TGF). 
slight shift ( $\delta=4.72 \mathrm{ppm})$. By contrast, the signals of the ethylene protons are almost combined into one single peak ( $\delta=3.67$ and $3.65 \mathrm{ppm})$ (Figure 1), which can be explained by a higher conformational flexibility of the polymeric backbone. Likewise, the ${ }^{13} \mathrm{C}$ NMR spectrum of the polymer shows a close similarity with that of the monomer. These data allow to conclude that no rearrangements occur during polymerization and thus the polymer is built up of a regular sequence of one methylene group

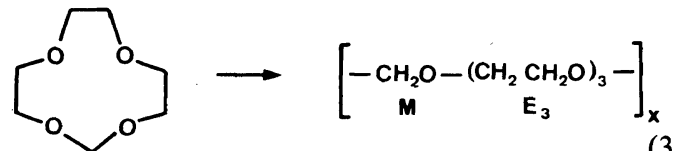

and 3 ethylene groups (eq 3); thus the polymer has the structure of a "sequenced copolymer." According to IUPAC nomenclature ${ }^{17}$ this polymer would be a "regular polymer" but differs from an alternating copolymer insofar as it does not necessarily show a $1: 1$ ratio of monomer units, but can be comprised of a variety of other monomer ratios, instead. The polymerization reaction can be followed by high-performance gel-permeation chromatography (HP-GPC) which reveals the formation of a mixture of a polymer fraction and a series of oligomers. A typical GPC trace is shown in Figure 2. The quantitative analysis of the components by means of a calibration curve allows to determine time-conversion curves for the consumption of monomer and the formation of oligomers and polymers (Figure 3). A characteristic S-shaped curve for the formation of the polymer is obtained which has also been described by Yamashita ${ }^{11,12}$ who therefore postulated a two-stage polymerization mechanism. The most important feature of this polyreaction is that a stationary state is attained after a definite time ( $30 \mathrm{~min}$ in the example shown). At depolymerization under identical conditions, the same ratios of monomer, oligomers, and polymers are obtained as could be shown by Yamashita's and our own studies. ${ }^{13}$ That means that the polymerization proceeds in a true equilibrium reaction. It should be mentioned that this behaviour is in contrast with the polymerization of 1,3,5-trioxepane, where dioxolane and formaldehyde are formed in addition to monomer and polymer in the stationary state. ${ }^{18,19}$

The formation of linear and cyclic oligomers has been well known from many polymerization and

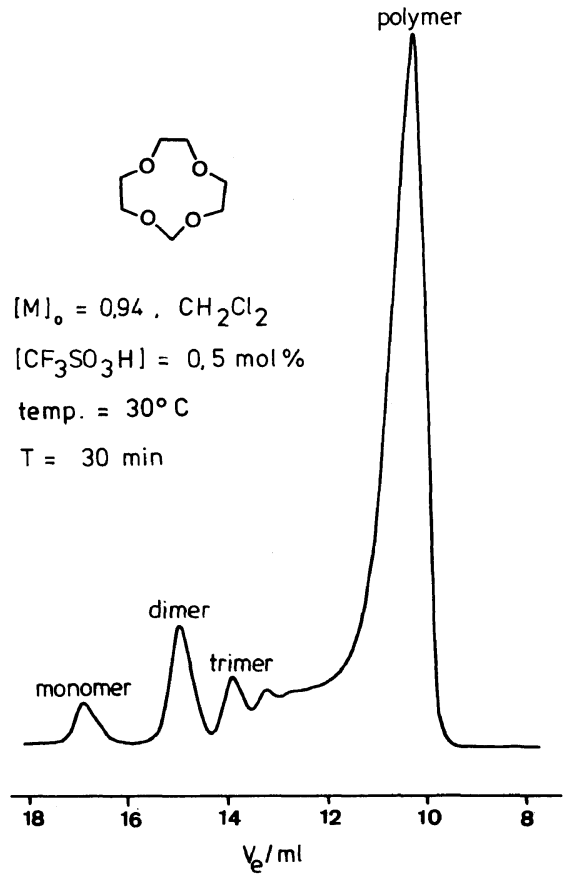

Figure 2. HP-GPC curve of the reaction mixture during the polymerization of 1,3,6,9-tetraoxacycloundecane (TGF).

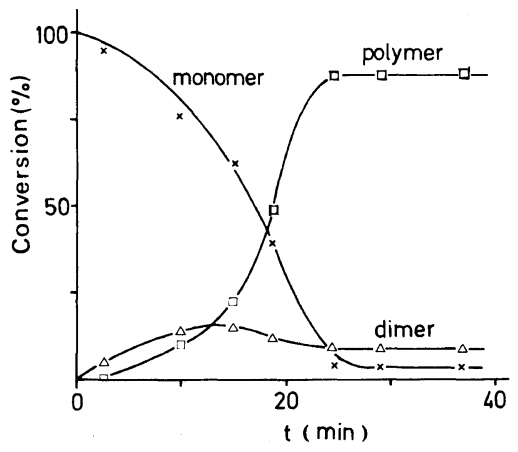

Figure 3. Time-conversion curve of the polymerization of 1,3,6,9-tetraoxacycloundecane: $[\mathrm{M}]_{0}=0.5 \mathrm{~mol}$ $1^{-1}$ in $\mathrm{CH}_{2} \mathrm{Cl}_{2} ;\left[\mathrm{CF}_{3} \mathrm{SO}_{3} \mathrm{H}\right]=0.1 \mathrm{~mol} \%$; temp, $0^{\circ} \mathrm{C}$.

polycondensation reactions. ${ }^{20-22}$ It was therefore of interest to study the formation of oligomers of TGF at various polymerization conditions. Figure 4 shows that the formation of dimer is enhanced with decreasing concentration of monomer. Increased concentrations of monomer yield enhanced for- 


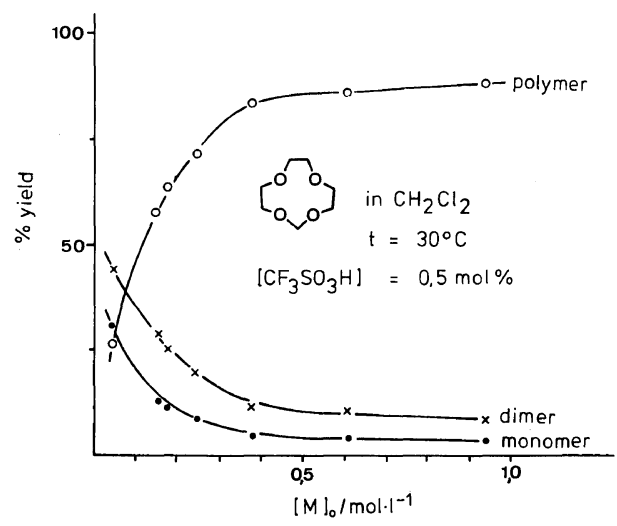

Figure 4. The composition of the reaction mixture in the equilibrium as a function of the initial monomer concentration.

mation of polymer, with accordingly higher degrees of polymerization. We have successfully isolated the first eight homologous oligomers from the polymerization mixture in preparative amounts. ${ }^{14}$

It could be shown that all oligomers are cyclic compounds, having the same sequence as the monomer and ring sizes of 11 and multiples thereof. The melting points as a function of ring size show an unusual behaviour ${ }^{15}$ (Figure 5). Oligomers with even ring sizes always have higher melting points than those with odd ring-size numbers; the melting points decrease with increasing molecular weights and eventually a melting point of $5-6^{\circ} \mathrm{C}$ for the polymer is reached. By contrast, saturated cyclic hydrocarbons of similar sizes show an increasing tendency of melting points with increasing ring $\operatorname{size}^{23}$ (Figure 5). By improved high-resolution GPC technique, the presence of higher oligomers up to a degree of polymerization of approximately 20 could be established. ${ }^{16}$ The finding that these oligomers show a $\log M-V_{\mathrm{e}}$ dependancy identical to the lower cyclic oligomers $(x=3-8)$, and the absence of other oligomers indicate that the polymerization mixture is exclusively comprised of macrocyclic species, at least up to a degree of polymerization of 20 (which corresponds to ring-size numbers of $22-220$ or molecular weights of 324 to 3240). There are no linear species in this molecular weight range. According to the Jacobson-Stockmayer theory ${ }^{24-26}$ a relation for the equilibrium constant between cyclic and linear oligomers exists which, with certain assumptions, can be expressed by the following equation.

$$
\lg \left[\mathrm{M}_{x}\right]_{\mathrm{e}}=a-2.5 \lg x
$$

In this equation, $x$ is the degree of polymerization of the cyclic oligomer, $\left[\mathbf{M}_{x}\right]_{e}$ the equilibrium concentration of cyclic oligomer, and $a$ a constant. According to Semlyn, this equation can be applied to ring-chain-equilibria as well as to ring-ring-

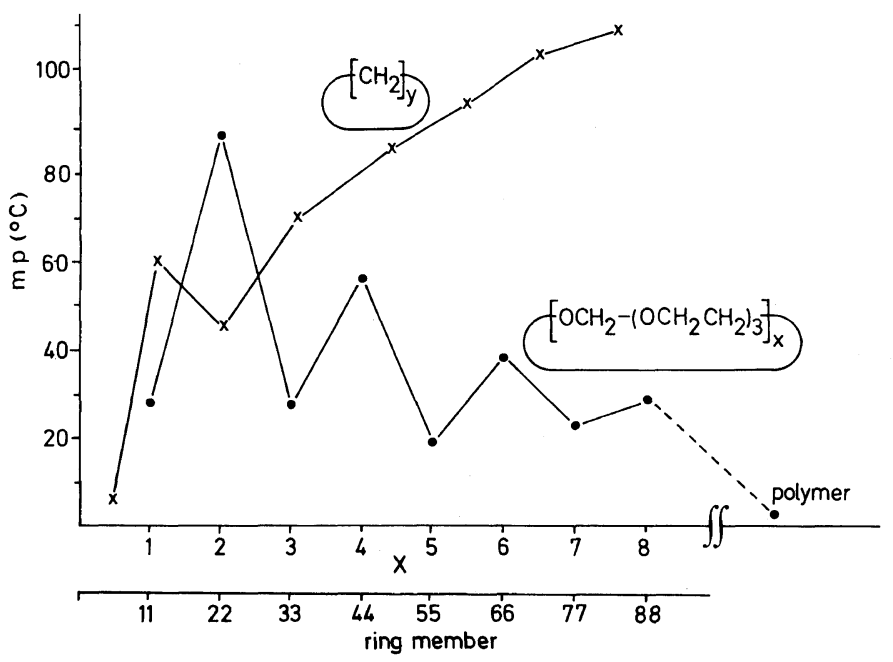

Figure 5. Melting points of cycloalkanes (+) and cyclic oligomers of TGF $(\odot)$ as a function of polymerization degree $X$ or ring size. 


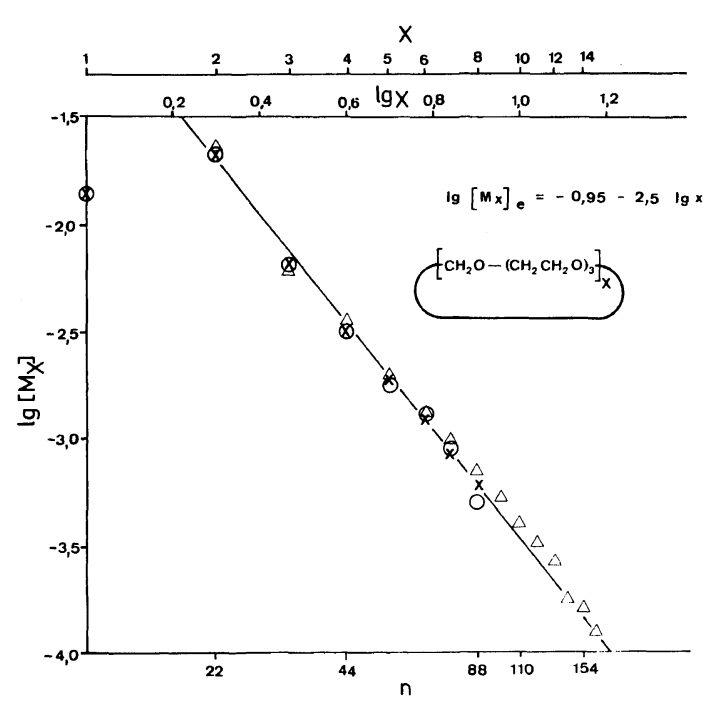

Figure 6. $\log -\log$ plot of the equilibrium concentration of cyclic oligomers of TGF and polymerization degree $X$ (eq 4): $\Delta, \times$, and $\bigcirc$, different experiments; $n$, ring size.

equilibria. The concentrations of cyclic oligomers determined from GPC curves plotted according the eq 4 yields a linear function with a slope of -2.5 (Figure 6), and a value for the constant $a=-0.95$ for $x=2-15$ (for oligomers with $x>16$, an exact quantitation from the GPC curve was not possible). ${ }^{16}$ From the value of the constant $a$ a characteristic ratio $C_{\infty}=7.8$ can be calculated. This applicability of eq 4 over a wide range of the cyclic oligomers is remarkable. In many other cases with ring-chain-equilibria deviations occur at low oligomer sizes. It can be further concluded from these results that, at the polymerization conditions used, the polymer mixture is comprised of at least $55-60$ $\mathrm{wt} \%$ macrocyclic species. It is still uncertain whether the high-molecular-weight fractions also consist of cyclic macromolecules or whether linear polymers are present. This question is currently being investigated. Preliminary viscosity data suggest that even the high-molecular-weight fractions consist at least partially of cyclic macromolecules.

There are several models in the literature about the mechanism of the ring-opening polymerization of oxacyclic compounds. A major problem to attack this question is the identification and quantitation of the active end group species which, because of their very low concentrations, requires particularly sensitive analytical techniques. Several methods have been recommended in the literature. We applied some of them in order to elucidate the formation of cyclic oligomers and polymers during polymerization of TGF. The experiments are not yet finished.

However, in the light of the currently available data, the following scheme for the polymerization of TGF can be proposed: the protonated monomer forms, by ring opening, an oxycarbenium ion which is in equilibrium with the trifluoromethanesulfonic ester or forms a $t$-oxonium ion by addition to the oxygen atom of a monomer or a polymer. Propagation of the chain proceeds in an equilibrium polymerization by nucleophilic attack of the monomer; the growing chain ends form cyclic oligomers and cyclic polymers by back-biting reactions. These cyclic macromolecules are unable to further propagate ("sleeping polymers," according to Szwarc) but can be re-initiated by protonation, which leads to further propagation and/or depropagation. Because of the very low concentration of open, growing chains, the isolated polymer contains primarily cyclic compounds and only small amounts of linear chains. Since these polymers are easily hydrolyzable because of the acetals bonds, linear macromolecules can be formed afterwards by ring opening during isolation and purification.

In a temperature range of $-30^{\circ} \mathrm{C}$ to $+30^{\circ} \mathrm{C}$ a polymerization enthalpy of $-7.75 \pm 0.37 \mathrm{~kJ} \mathrm{~mol}^{-1}$ was found which is in good agreement with the value of $-9.2 \pm 1.25 \mathrm{~kJ} \mathrm{~mol}^{-1}$ determined by Yamashita, ${ }^{11}$ while our value of $+6.78 \pm 1.34 \mathrm{~kJ}$ $\mathrm{mol}^{-1}$ for the polymerization entropy differs from that of Yamashita who found a $\Delta S_{\mathrm{ss}}$ of close to zero. Thus, the ceiling temperature of TGF must be very high. To confirm this, we carried out the polymerization of temperature up to $155^{\circ} \mathrm{C}$. At this temperature, the monomer is completely stable and does not spontaneously polymerize or degrade. In the presence of catalysts, polymerization takes place, indeed.

\section{Polymerization of Homologous with Ring Sizes of 14 and 17 Atoms}

Tetraethylene glycol formal (1,3,6,9,12-pentaoxacyclotetradecane) (POC), the next higher homologous of TGF is prepared in analogous manner and has similar properties. ${ }^{10}$ POC can also be polymerized at similar conditions, as already 


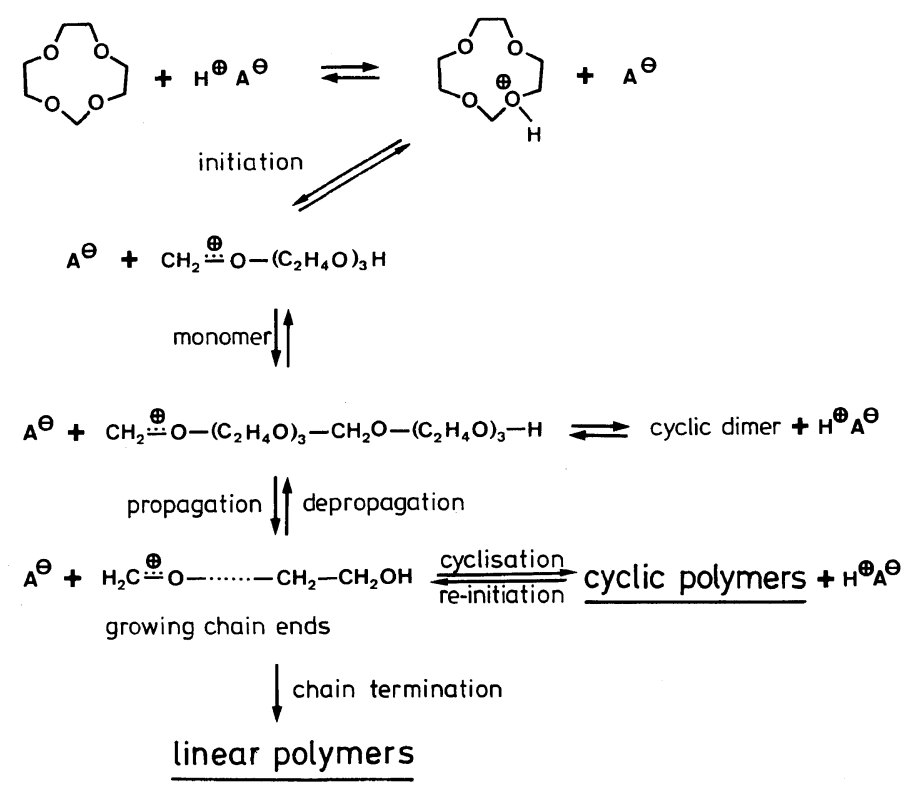

Figure 7. Mechanism of the polymerization of TGF wth $\mathrm{CF}_{3} \mathrm{SO}_{3} \mathrm{H}\left(\mathrm{H}^{\oplus} \mathrm{A}^{\ominus}\right)$.

described by Yamashita, ${ }^{11}$ under formation of cyclic oligomers and polymers in an equilibrium reaction. The polymers are highly viscous or waxlike materials and can be isolated by fractionated precipitation from methanol-water and ether at $0^{\circ} \mathrm{C}$. Like TGF, the ${ }^{1} \mathrm{H}$ NMR spectrum of the polymer shows a singlet for the methylene protons at $\delta=4.73 \mathrm{ppm}$ (monomer, $\delta=4.7 \mathrm{ppm}$ ) and a combined signal for the ethylene protons $(\delta=3.68$ ppm) which appear as two separate peaks in the monomer spectrum.

We assume a polymer structure of a regular, sequenced copolymer $\left(\mathrm{ME}_{4}\right)$ since there are no indications for a different structure. Thus, it<smiles></smiles>

possesses similar properties as poly(ethylene oxide) (POE), e.g., it forms inclusion complexes with urea quite similar as POE.

Finally we prepared pentaethylene glycol formal (HOC), starting from pentaethylene glycol synthesized according to Krespan. ${ }^{27} \mathrm{HOC}$ is a colourless, highly viscous liquid with a melting point of $-6.5^{\circ} \mathrm{C}$ and a boiling point of $86^{\circ} \mathrm{C}(0.01$ Torr $)$. Its polymerization with trifluoromethanesulfonic acid in $\mathrm{CH}_{2} \mathrm{Cl}_{2}$ was found analogous to the other homologues and will not be further described. Elemental and NMR analysis of the polymer confirm the expected structure of 1 oxymethylene and 5 oxyethylene units $\left(\mathrm{ME}_{5}\right)$. Thus, we have established a homologous series of sequenced copolymers with the general formula

$$
\left.\mathrm{f}\left(\mathrm{OCH}_{2}\right)_{a}\left(\mathrm{OC}_{2} \mathrm{H}_{4}\right)_{b}\right\rceil_{X} \text { and } a=1, b=1-5 \text {. }
$$

It was expected that the properties of these polymers should be between that of poly(oxymethylene) $(b=0)$ (POM) and poly(oxyethylene) $(a=0)$ (POE). To prove this, we determined the melting points of the polymers after re-precipitation and lyophilization from benzene. $4-6 \mathrm{mg}$ samples were cooled under $\mathrm{N}_{2}$ in a DTA instrument down to $-20^{\circ} \mathrm{C}$ with a rate of $0.1^{\circ} \mathrm{C} \mathrm{min}-1$ and then heated up at $5^{\circ} \mathrm{C} \mathrm{min}^{-1}$. The melting point was taken from the maximum of the endothermal peak. The sample was then cooled again, annealed slightly below the melting point for several hours, and then the melting point was redetermined. The melting points so obtained are listed in Table I. Poly(TGF) has the lowest melting 


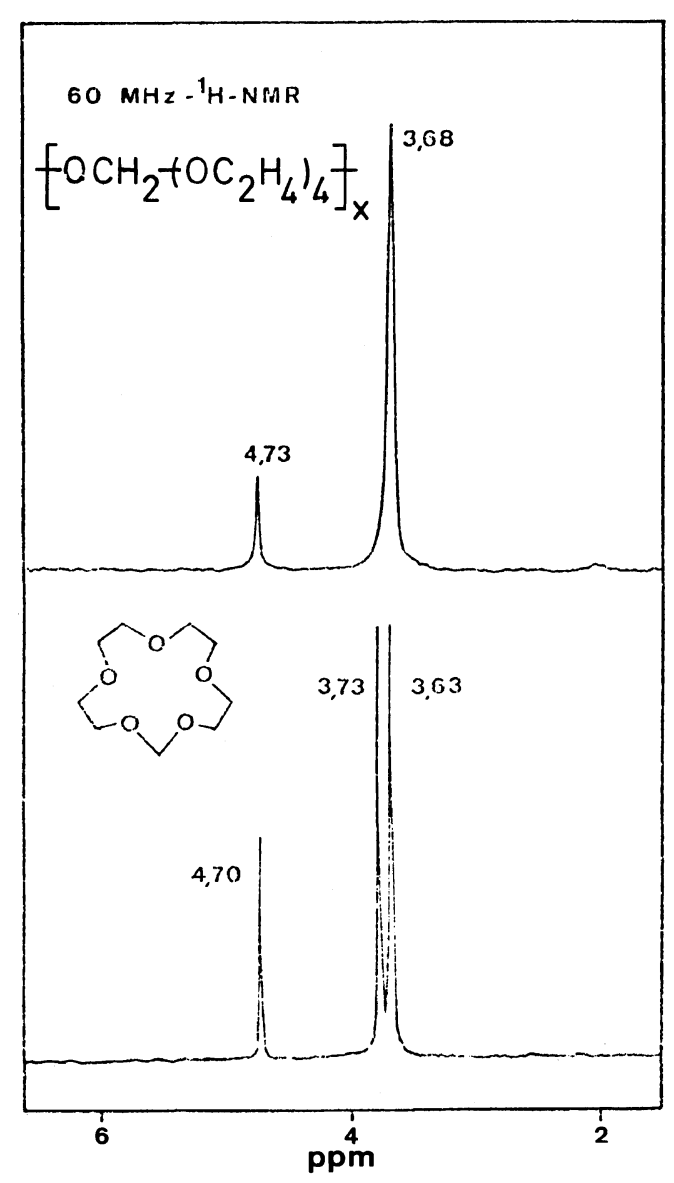

Figure 8. ${ }^{1} \mathrm{H}$ NMR spectra of monomer and polymer 1,3,6,9,12-pentaoxacyclotetradecane (POC). point in this series.

\section{Polymerization of 1,3-Dioxacycloundecane (OMF)} and 1,3,6,11-Tetraoxacyclotridecane (DDF)

These compounds contain less oxygen than the monomers described above; they should also yield regular copolymers, but with different sequences.

OMF has not yet been described in the literature. Like TGF it can be prepared by thermolysis of a prepolymer of 1,8-octanediol and paraformaldehyde, with yields of $10-20 \%$. OMF is a colourless, irritant liquid (bp $196^{\circ} \mathrm{C} ; 25-30^{\circ} \mathrm{C}$ at $0.01 \mathrm{Torr} ; \mathrm{mp}$ $-62^{\circ} \mathrm{C}$ ). Its structure was confirmed by IR-, ${ }^{1} \mathrm{H}$, and ${ }^{13} \mathrm{C}$ NMR spectroscopy.

OMF can be polymerized with various cationic initiators.

We used preferentially trifluoromethanesulfonic acid and followed the polymerization by HP-GPC. The HP-GPC curve shows a series of oligomers and the formation of polymers. Under the conditions used a stationary state is reached after 2 hours.

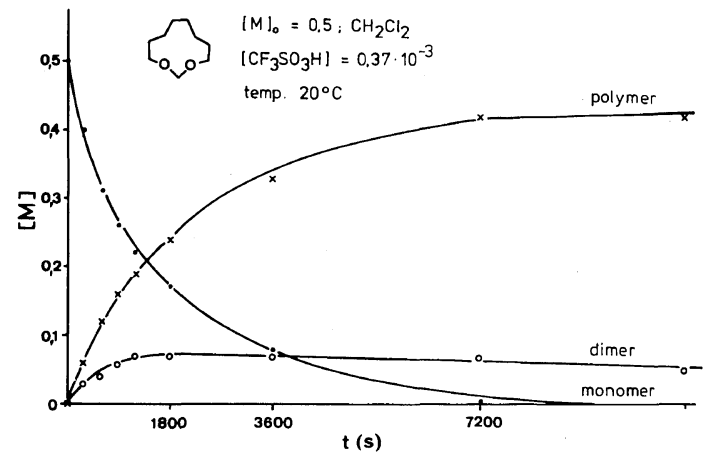

Figure 9. Time-conversion curve of the polymerization of 1,3-dioxacycloundecane (OMF).

Table I. Melting points $\left(T_{\mathrm{m}}\right)$ and glass-transition temp $\left(T_{\mathrm{g}}\right)$ for polymers of the general formula $\left[\left(\mathrm{OCH}_{2}\right)_{1}\left(\mathrm{OC}_{2} \mathrm{H}_{4}\right)_{n}\right\}_{x}$

\begin{tabular}{|c|c|c|c|c|}
\hline Polymer of & $n$ & $\frac{T_{\mathrm{m}}}{{ }^{\circ} \mathrm{C}}$ & $\frac{T_{\mathrm{g}}}{{ }^{\circ} \mathrm{C}}$ & $\rho_{\mathrm{M}}^{\mathrm{a}}$ \\
\hline Dioxolane & 1 & 60 & -68 & 0.50 \\
\hline Trioxolane & 2 & 38 & -67 & 0.33 \\
\hline TGF & 3 & 5 & -63 & 0.25 \\
\hline POC & 4 & 27 & -62 & 0.20 \\
\hline $\mathrm{HOC}$ & 5 & 29 & -62 & 0.17 \\
\hline
\end{tabular}

a $\rho_{\mathrm{M}}=1 /(1+n)$ (mol ratio of oxymethylene units). 
Noticeably, we did not find residual monomer at equilibrium, and no S-shaped curve of polymer formation. During depolymerization under similar conditions an identical series of oligomers without traces of monomer was found. The use of $\mathrm{BF}_{3}$ etherate as initiator considerably slows down the polymerization, with the equilibrium attained after 48 hours. Again, there is complete consumption of monomer. This means that the monomer is totally consumed during propagation but not regenerated during depropagation or back-biting reactions.

Instead, cyclic dimer or oligomers are cleaved off. Not only oligomers but high-molecular-weight polymers are formed already at low conversion. Therefore, a two-stage polymerization mechanism postulated by Yamashita, can be excluded in this case. All oligomers formed are again cyclic species. The dimer was isolated and identified as $1,3,12,14$ tetraoxacyclodocosane. It is a crystalline compound $\left(\mathrm{mp} 82^{\circ} \mathrm{C}\right.$ ) which apparently is formed preferentially because it is also built as a by-product during the synthesis of the monomer by thermolysis of the prepolymer mentioned above. The dimer can also be polymerized, but again no monomer is formed, which is in contrast with the polymerization of the cyclic dimer of TGF. Polymers with molecular weights of approximately 10,000 are obtained from either monomeric or dimeric OMF. In this case, the polymer structure can be described as a $1: 1$ alternating copolymer of oxymethylene and oxyoctamethylene units $\left.\mathrm{fOCH}_{2}-\mathrm{O}\left(\mathrm{CH}_{2}\right)_{8}\right\}_{X}$.

As a consequence, their properties are different from the copolymers described above, e.g., they are soluble in $\mathrm{CH}_{2} \mathrm{Cl}_{2}, \mathrm{CHCl}_{3}$, benzene, and toluene, but insoluble in alcohols and water. The polymer is a solid at ambient temperature, with a crystalline $\mathrm{mp}$ of $49^{\circ} \mathrm{C}$ (DTA).

Finally, a further new macrocyclic acetal comprised of 1 oxymethylene (M), 2 oxyethylene (E), and 1 oxybutylene (B) units shall be mentioned briefly. The synthesis and properties of 1,3,6,11tetraoxacyclotridecane (DDF) will be reported elsewhere. This compound can be easily polymerized by cationic initiation. Again, an equilibrium between polymer and cyclic oligomers is formed, with monomer present in the equilibrium mixture. The polymer is soluble in many organic solvents and in $\mathrm{H}_{2} \mathrm{O}$ but insoluble in ether and hydrocarbons. Molecular weights of approximately 25,000 are obtained for the high-molecular-weight fractions.

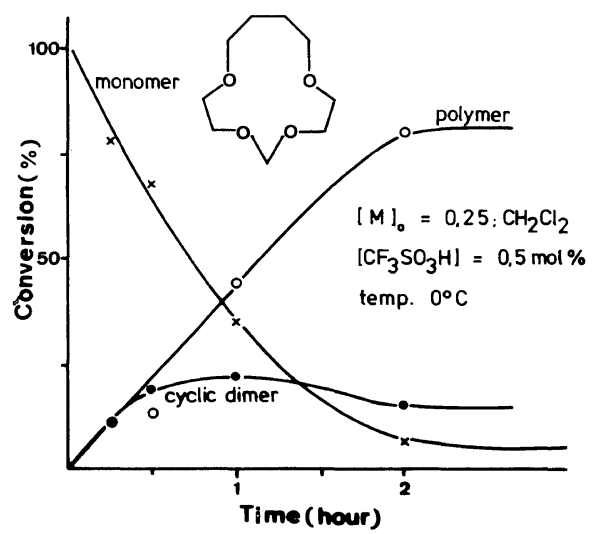

Figure 10. Time-conversion curve of the polymerization of 1,3,6,11-tetraoxacyclotridecane (DDF).

Its structure is that of a terpolymer with the sequence $f-M-E-B-E-t_{X}$.

\section{RADICAL AND IONIC POLY- MERIZATION OF 2-ISOPROPENYL- NAPHTHALENE (2-IPN)}

This compound is not simple to produce in the laboratory, and this is presumably the reason why little is known in the literature on its polymerization. The Bergbau $\mathrm{AG}^{28}$ has recently developed a technical process for its production, and the monomer is now available in high purity.

2-IPN is a colorless crystalline compound (mp $54^{\circ} \mathrm{C}$ ).

The UV spectrum shows three maxima

$$
\begin{gathered}
\left(\varepsilon_{296}=8526 \pm 160 ; \varepsilon_{284}=11454 \pm 280 ;\right. \\
\left.\varepsilon_{275}=9415 \pm 3001 \mathrm{~mol}^{-1} \mathrm{~cm}^{-1}\right)
\end{gathered}
$$

The ${ }^{1} \mathrm{H}$ NMR spectrum shows the following signals:

$\delta 2.1\left(\mathrm{~s}, 3 \mathrm{H}, \mathrm{CH}_{3}\right) ; \delta 5.05\left(\mathrm{~s}, 1 \mathrm{H}, \mathrm{CH}_{2}\right) ; \delta 5.45(\mathrm{~s}, 1 \mathrm{H}$, $\mathrm{CH}_{2}$ ); and 7.0-7.8 ppm (m, 7H, naphthyl).

All attempts to polymerize 2-IPN using AIBN in THF at $65^{\circ} \mathrm{C}$ or at $-10^{\circ} \mathrm{C}$ with UV, failed.

Earlier work on the radical copolymerization with acrylonitrile ${ }^{29}$ was, however, confirmed by us. We then turned our attention to the copolymerization between 2-IPN and maleic anhydride (MSA).

A yellow colour appears on the mixing of 
solutions of both components, presumably due to a charge-transfer (CT) complex (Figure 11). We have measured the equilibrium constant for the complex formation by two different methods (in $\mathrm{CH}_{2} \mathrm{Cl}_{2}$ at $20^{\circ} \mathrm{C}$ ). By UV measurement a value of $K=0.22$ $( \pm 20 \%) \mathrm{kg} \mathrm{mol}^{-1}$ was obtained, and the more accurate NMR method gave $0.23( \pm 4 \%) \mathrm{kg}$ $\mathrm{mol}^{-1} \cdot 30$

Some years ago, Yamashita ${ }^{31}$ proposed for pairs of monomers a relationship between the complex formation and their tendency to copolymerize. In this case copolymerization should then occur very readily, and Hallensleben and coworkers ${ }^{32}$ has indeed reported that a mixture of 2-IPN and MSA gave high yields of an alternating $1: 1$ copolymer under radical conditions. We could not reproduce his results, however. Under the given conditions ([2IPN $]=1-3 \quad \mathrm{moll}^{-1} ; \quad[\mathrm{MSA}]=3-1 \quad \mathrm{moll}^{-1}$; $[\mathrm{AIBN}]=0.03 \mathrm{~mol} \%$; toluene, $60^{\circ} \mathrm{C}$ ) a mixture was obtained which consisted primarily of a crystalline substance and only a minimal amount of copolymer. The copolymer is insoluble in benzene and was thus separated from the crystalline compound. The polymer melted at $c a .290^{\circ} \mathrm{C}$ and contained more MSA (according to elemental analysis) as was required for a $1: 1$ alternating copolymer. The exact structure has not yet been determined. The crystalline substance was identified as a Diels-Alder adduct from 2-IPN and MSA. (Figure 11). Presumably the CT complex facilitates the formation of this compound. We have tried to avoid the Diels-Alder reaction by lowering the temperature. The photolysis of AIBN at $15^{\circ} \mathrm{C}$, and redox systems based on boralkyl-hydroperoxide at $0^{\circ} \mathrm{C}^{33}$ were both used to initiate the polymerization. The conversions are $36 \%$ and $4 \%$, respectively, but under these conditions one really obtains only copolymers

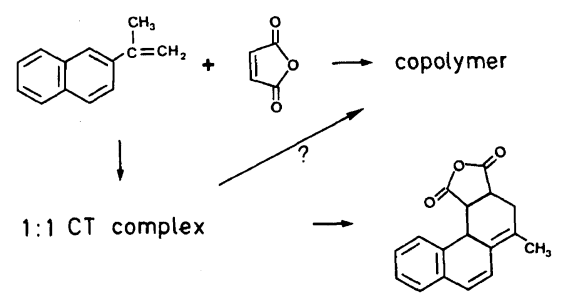

Figure 11. Formation of CT-complex, adduct, and copolymer of 2-isopropenylnaphthalene and maleic anhydride.
(Figure 11). Further research on the copolymerization of 2-IPN with other monomers is under way.

It was assumed that 2-IPN could be polymerized under cationic conditions, by analogy to $\alpha$-methylstyrene and 2-vinylnaphthalene. Trifluoromethanesulfonic acid, $\mathrm{BF}_{3}$-etherate, and $\mathrm{SnCl}_{4}$ were used as initiators. (Reaction conditions: $+20^{\circ} \mathrm{C}$ and $-20^{\circ} \mathrm{C}, 20$ hours). ${ }^{34}$

The monomer was completely consumed but no high polymer was formed, only a mixture of oligomers from which a compound with a melting point of $120^{\circ} \mathrm{C}$ and a molecular weight of 336 (mass spectrum) could be isolated. This compound was identical with a dimer prepared by another route and already described in the literature..$^{35,36}$

The analysis of the reaction mixture by gelchromatography showed a homologous series of oligomers with a maximum degree of polymerization of 5 . Higher polymers were not obtained despite variation of the experimental conditions. (Figure 12). A strong chain-transfer reaction with

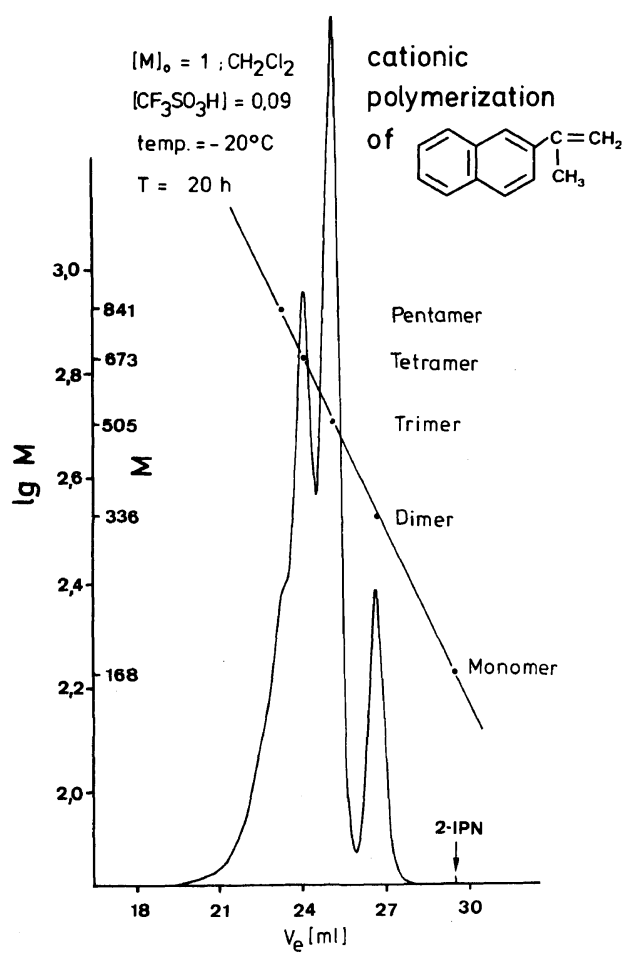

Figure 12. HP-GPC curve and $\log M-V_{\mathrm{e}}$ plot of the reaction mixture during cationic poymerization of 2 isopropenylnaphthalene. 
the monomer is the likely cause. For the same reason, copolymers (e.g., with styrene) could not be obtained. Ziegler-Natta catalysts also gave only oligomers.

In 1963 Hopff and Lüssi ${ }^{37}$ mentioned the anionic polymerization of 2-IPN and found a ceiling temperature of $+24^{\circ} \mathrm{C}$.

We used these observations as a starting point in our own experiments, in which we carried out the polymerization in THF using butyllithium between 0 and $-78^{\circ} \mathrm{C}$. The solutions went dark-green immediately on addition of the initiator. After several hours the polymer was obtained as a colorless powder on addition of methanol. The polymer is easily soluble in THF, $\mathrm{CH}_{2} \mathrm{Cl}_{2}$, toluene, chloroform, and boiling cyclohexane but unsoluble in ether, alcohols, and ketones. It melts at $c a .280^{\circ} \mathrm{C}$ and decomposes above $300^{\circ} \mathrm{C}$.

DTA measurements give a glass-transition temperature of $220^{\circ} \mathrm{C}$; thus being considerable higher as $\operatorname{poly}(\alpha$-methylstyrene $)\left(150-180^{\circ} \mathrm{C}\right)$, poly $(1-$ vinylnaphthalene) $\left(159^{\circ} \mathrm{C}\right), \quad$ and $\operatorname{poly}(2-$ vinylnaphthalene) $\left(150^{\circ} \mathrm{C}\right)$. Light scattering gave molecular weights between 10000 and 300000 depending on the polymerization conditions. Carefully controlled conditions lead to a narrow molecular weight distribution, for instance values of $M_{w} / M_{n}$ between 1.08 and 1.15 were obtained. For the $[\eta]-M$ relationship, (in THF) we found $[\eta]=K$ $M^{\alpha} ; K=1.7 \times 10^{-2} \mathrm{ml} \mathrm{g}^{-1} ; \alpha=0.64$. Polymeric 2IPN is an electron-donor [as is polyvinylnaphthalene] and gives deeply coloured CT complexes with electron acceptors. The colours range from blue-black (tetracyanoethylene) through deep green (dichlorodicyanoquinone), green (tetracyanoquinodimethane) to deep yellow (trinitrobenzene).

Polymerization proceeds on addition of butyllithium to equimolar mixtures of 2-IPN with methyl methacrylate or methacrylonitrile in THF at $-78^{\circ} \mathrm{C}$, but no copolymers are formed. Pure poly(MMA) or polymethacrylonitrile are obtained. It is, however, possible to prepare block copolymers in the following manner. First 2-IPN is completely polymerized under conditions leading to a living polymer, then methacrylonitrile, methyl methacrylate or 4-vinylpyridine is added. Addition of ethanol/ether after a further 20 hours precipitates the polymer. Homopolymers or by-products can be separated by extractions. Block copolymers from 2 -
IPN and butadiene are of particular interest, and further experiments in this direction are in progress.

Acknowledgement. We should like to express our thanks to "Deutsche Forschungsgemeinschaft" for the financial support within the research program of "Sonderforschungsbereich 41." Furthermore we thank Prof. Dr. G. Kölling and Dr. K. Handrick, Bergbau-Forschung GmbH, Essen.

\section{REFERENCES}

1. N. G. Gaylord, J. Polym. Sci., C, 31, 247 (1970).

2. M. Hirooka et al., J. Polym. Sci., B, 5, 47 (1967); J. Polym. Sci., Polym. Chem. Ed., 11, 1281 (1973).

3. J. Furukawa, J. Polym. Sci., Polym. Symp., No. 51, 105 (1975).

4. T. Saegusa, Makromol. Chem., Suppl., 3, 157 (1979).

5. M. Szwarc, "Carbanions, Living Polymers and Electron Transfer Processes," Interscience Publishers, New York, N.Y., 1968.

6. J. P. Kennedy, Makromol. Chem., Suppl., 3, 1 (1979).

7. K. Weissermel, E. Fischer, and K. Gutweiler, Kunststoffe, 54, 410 (1964).

8. D. Weichert, J. Polym. Sci., C, 16, 2701 (1967).

9. J. W. Hill and W. H. Carothers, J. Am. Chem. Soc., 57, 925 (1935).

10. K. Albrecht, D. Fleischer, C. Rentsch, H. Yamaguchi, and R. C. Schulz, Makromol. Chem., 178, 3191 (1977).

11. Y. Yamashita, Y. Kawakami, Am. Chem. Soc. Symp. Ser., 59, 99 (1977).

12. Y. Yamashita, Preprints, 26th IUPAC Symposium on Macromolecules, Mainz, 1979, Vol. 1, p 196.

13. R. C. Schulz, K. Albrecht, C. Rentsch, and Q. V. Tran Thi, Am. Chem. Soc. Symp. Ser., 59, 77 (1977).

14. C. Rentsch and R. C. Schulz, Makromol. Chem., 178, 2535 (1977).

15. K. Albrecht, D. Fleischer, A. Kane, C. Rentsch, Q. V. Tran Thi, and H. Yamaguchi, Makromol. Chem., 178, 881 (1977).

16. C. Rentsch and R. C. Schulz, Makromol. Chem., 179, 1403 (1978).

17. Pure Appl. Chem., 40, 479 (1974).

18. M. Szwarc and C. L. Perrin, Macromolecules, 12, 699 (1979).

19. M. Szwarc, Makromol. Chem. Suppl., 3, 327 (1979).

20. J. A. Semlyn, Adv. Polym. Sci., 21, 41 (1976).

21. E. J. Goethals, Adv. Polym., Sci., 23, 103 (1977).

22. A. Horbach, $\mathbf{H}$. Vernaleken, and $\mathbf{K}$. Weirauch, Makromol. Chem., 181, 111 (1980).

23. H. Höcker and K. Riebel, Polym. Prepr., Am. Chem. Soc., Div. Polym. Chem., 18, 489 (1977).

24. H. Jacobson and W. H. Stockmayer, J. Chem. Phys., 18, $1600(1950)$.

25. P. J. Flory and J. A. Semlyn, J. Am. Chem. Soc., 88, 


\section{Copolymers by Ionic Polymerization}

3209 (1960).

26. J. A. M. Andrews, F. R. Jones, and J. A. Semlyn, Polymer, 15, 420 (1974).

27. C. G. Krespan, J. Org. Chem., 39, 2351 (1974).

28. Bergbau-Forschung GmbH, D-4300 Essen/FRG, K. Handrick, Erdöl und Kohle, Compendium 1976/1977. Suppl. p 308.

29. K. W. Doak, M. A. Deahl, and J. H. Christmas, Polym. Prepr., Am. Chem. Soc., Div. Polym. Chem., 1, 151 (1960).

30. D. Engel and R. C. Schulz, Makromol. Chem., 180, 2987 (1979).

31. T. Kokubo, S. Iwatsuki, and Y. Yamashita,
Macromolecules, 1, 482 (1968).

32. M. L. Hallensleben and I. Lumme, Makromol. Chem., 144, 261 (1971).

33. A. Akimoto, unpublished results.

34. D. Engel and R. C. Schulz, Makromol. Chem., 180, 2991 (1979).

35. A. Fritz and R. W. Rees, J. Polym. Sci., A-1, 10, 2365 (1972).

36. L. A. Paquette and T. R. Phillips, J. Org. Chem., 30, 3883 (1965).

37. U. Hopff and H. Lüssi, Makromol. Chem., 62, 31 (1963). 